\title{
DISTINGUISHING INTERNAL, EXTERNAL AND GROUNDED RELATIONS
}

\author{
Bo R. Meinertsen
}

Published in Grazer Philosophishe Studien 83 (2011), 113-122

\begin{abstract}
I defend an ontological distinction between three kinds of relation: internal, external and grounded relations. Even though, as we shall see, this trichotomy is basic, it is not found in influential contemporary metaphysics. Specifically, the widespread tendency, exemplified notably by David Armstrong, of not recognizing grounded relations as distinct from external relations, can be shown to be mistaken. I propose a definition of each of the three kinds of relation. Of vital importance to the parsimony of metaphysics, I also argue that only external relations are ontologically fundamental.
\end{abstract}

\section{Introduction}

Consider relations such as being larger than holding between 20 and 15, being darker than holding between navy and cobalt, and being contrary to holding between triangularity and squareness. ${ }^{1}$ Contrast these with relations such as being in front of holding between the chair and the desk, standing next to holding between Sam and Kim; and being earlier than holding between Caesar's 18th-year birthday and his crossing the Rubicon. $^{2}$ A familiar view in contemporary metaphysics (cf. e.g. Armstrong 1997, 2004;

\footnotetext{
${ }^{1}$ It may well be that internal relations also include formal or topic-neutral relations, such as instantiation and entailment, in addition to the 'topic-specific' ones mentioned here. For a detailed examination of this and related issues, see Mulligan (1998).

${ }^{2}$ Note that the classification of this last example with the two preceding cases presupposes that the times of events are not essential to them (cf. sec. 2 below). This is a contentious view. Lawrence Brian Lombard (1986, 213ff) argues that an event's time of occurrence is essential to it. Lewis (1983) denies this, though for reasons that are intimately linked to his particular metaphysics. Who is right? Perhaps, as Bennett $(1988,60 \mathrm{ff})$ maintains, there are no 'hard' facts of the matter to enable us to find out.
} 
Mulligan 1998), call it the Standard View, is that the former kind of relations are internal and the latter are external and this distinction is exhaustive and mutually exclusive. However, I shall argue that there are not just two basic kinds of relation, but three: in addition to internal relations, there are two kinds of non-internal relation: external and grounded relations. I shall additionally argue that only external relations are ontologically fundamental. This has the added attraction that we only need to include this kind of relation in our ontological economy. The reason for this is that, other things being equal, arguably only ontologically fundamental entities are a cost in this economy. Given this, my position is of course just as ontologically parsimonious as the Standard View conjoined with the claim that only external relations are ontologically fundamental in the sense at issue (Armstrong 1997, 2004).

\section{Internal and external relations}

Our first task is to define internal and external relations properly. Roughly, an internal relation is a relation that is entailed by its relata. Hence, an internal relation is such that two entities with logical necessity must stand in it. ${ }^{3}$ Armstrong $(1997,12)$ accordingly defines a relation as being internal if and only if 'it is impossible that the terms should exist and the relation not exist', where the coexistence of the terms is possible. Or, as he puts it even more succinctly, a relation is internal when 'given just the terms of the relation, the relation between them is necessitated' $(2004,9)$. I suggest that the modality involved here is logical. So I propose the following definition (cf. Johansson 1989, 117):

\footnotetext{
3 For convenience of exposition, I shall, as is conventional in the literature, speak only about dyadic relations, assuming that what I say holds, mutatis mutandis, for the polyadic for $n>2$.
} 
(IR) A relation is internal iff it is logically impossible for its relata to coexist without the relation holding between them.

Thus, it is logically impossible for 20 and 15 to coexist without being larger than holding between them; for navy and cobalt to coexist without being darker than holding between them; and for triangularity and squareness to coexist without being contrary to holding between them.

Let us now turn to external relations. If one divides all relations into internal and external ones, then one can of course define them simply as 'not internal'. A negative definition of external relations as simple as this can be found in Armstrong (e.g. 1997, 87). Kevin Mulligan mentions another example of such a definition: 'A relation is said to be external if it need not relate the entities it does relate (Maria need not be next to Sam).' $(1995,246)$. A more detailed definition is found in Russell:

I maintain that there are such facts as that $x$ has relation $\mathrm{R}$ to $y$, and that such facts are not in general reducible to, or inferable from, a fact about $x$ only and a fact about $y$ only: they do not imply that $x$ and $y$ have any complexity, or any intrinsic property distinguishing them from a $z$ and a $w$ which do not have the relation $\mathrm{R}$. This is what I mean when I say relations are external. (1910, 374)

This definition is obviously also negative. But it adds to the above simple definition the substantial claim that there could be particulars exactly similar to the relata of an external relation which do not stand in it (i.e. particulars $x$ and y without 'any complexity, or any intrinsic property distinguishing them from a $z$ and a $w$ which do not have' this relation) . I will employ this addition to define external relations for the purposes of this paper. By 
'exact similarity' I understand this: two entities $x$ and $y$ are exactly similar if and only if they have all of their properties in common, i.e. for all properties $\mathrm{P}, x$ has $\mathrm{P}$ iff $y$ has $\mathrm{P} .{ }^{4}$ Call exactly similar entities 'duplicates'. Thus, I suggest that (cf. Johansson 1989, 119):

(ER) A relation is external iff it is logically possible for duplicates of its relata to coexist without the relation holding between them.

For instance, it is clearly logically possible for duplicates of my chair and desk to coexist without being in front of holding between them, or for duplicates of Sam and Kim to exist without being next to holding between them, and it is (perhaps, cf. footnote 2) logically possible for duplicates of Caesar's 18th-year birthday and his crossing the Rubicon to coexist without being earlier than holding between them. These examples of traditionally 'external' relations are therefore also classified as external on my view.

\section{Grounded relations: neither internal nor external}

But from this alone we cannot conclude or assume, in line with the Standard View, that external relations are the only kind of non-internal relation. For there is a second kind of non-internal relation, which I call grounded relations, following Ingvar Johansson (1999, ch. 8; cf. Campbell 1990, ch. 5). Many contemporary philosophers (e.g. Armstrong 1997, 2004; Vallicella 2002; cf. Mulligan 1998) only distinguish between external and internal relations (i.e. the term 'external relations' is often used both for what I call 'external relations' and 'grounded relations'), and therefore crudely categorize as external relations

\footnotetext{
${ }^{4}$ Here, as elsewhere in this paper, I consider only non-relational properties, since I believe relational properties are spurious.
} 
those relations that are grounded and (hence, given what I shall argue in the next section, mistakenly consider them ontologically fundamental). ${ }^{5}$

Roughly, a grounded relation is a relation that is entailed by certain contingent properties of its relata. Examples are being taller than holding between Kim who is $5 \mathrm{ft}$ 11ins and Sam who is 5ft 9ins and being happier than holding between Sam and Kim when Sam is happier than Kim. It is contingent that Kim and Sam have the heights they actually have, so it is possible (at least logically) that Kim is not taller than Sam, and it is similarly contingent that Kim and Sam have the levels of happiness they actually have, so it is possible (at least logically) that Sam is not happier than Kim. Hence, it is logically possible that Kim and Sam coexist without the grounded relation holding between them. But it is not similarly possible for particulars exactly similar to them (now) to coexist without the relation holding between them. Aiming for the same level of generality as in the previous definitions, I therefore suggest the following (cf. Johansson ibid. 120):

(GR) A relation is grounded iff it is logically impossible for duplicates of its (actual) relata to coexist without the relation holding between them.

This completes our tricomoty of relations. I consider it to be exhaustive: any relation is either internal or external or grounded. The distinction between each of the three kinds of relation is also exclusive; specifically, by (IR), (ER) and (GR), the pairs 'internal' and

\footnotetext{
${ }^{5}$ Note, however, that Armstrong in his early work on universals (1978) does not have this view. His notion of an internal relation there is very much like my notion of a grounded relation: 'Two or more particulars are internally related if and only if there exist properties of the particulars which logically necessitate that the relation holds' (ibid., 85). By contrast, it seems quite unclear what his 1978 view of an internal relation in our (and his) present sense is.
} 
'external', 'internal' and 'grounded' and 'external' and 'grounded', respectively, are contraries.

However, both grounded and external relations are non-internal, and this is one reason why the distinction between them can easily be overlooked. Equally, one can easily overlook the distinction between grounded and internal relations. For instance, being darker than, which I mentioned as an example of an internal relation, also seems to be an example of a grounded relation: it might, for example, hold between Sam's shirt and Kim's blouse when the former is navy and the latter is cobalt. But since, I shall assume, no relation can be internal in some cases and grounded (not internal) in others, we should hold that there are two relations which just have the same name (relation nominal); in the example, 'being darker than'. ${ }^{6}$

The relationship between an internal relation and a homonymous grounded one is intimate, however. To see this, we need first to analyse grounded relations. Consider again our initial example of being taller than holding between Kim and Sam when Kim is $5 \mathrm{ft} 11 \mathrm{ins}$ and Sam is $5 \mathrm{ft} 9 \mathrm{ins}$. Let us say that Kim is $5 \mathrm{ft} 11 \mathrm{ins}$ if and only if the fact of Kim's being $5 \mathrm{ft} 11$ ins exists and that Sam is $5 \mathrm{ft}$ 9ins if and only if the fact of Sam's being 5ft 9ins exists. But these two facts do not jointly suffice to ground being taller than. (I speak here in the material mode of 'grounding' rather than in the equivalent semantic

\footnotetext{
${ }^{6}$ It is beyond the scope of this paper to defend this assumption. I make it only for the sake of argument. However, it should be noted that one might attempt to defend it by arguing that internal and grounded relations are universals. Since a universal is numerically identical in each of its instantiations, by the Indiscernibility of Identicals, no relational universal is both internal and grounded. However, as I shall argue below, internal and grounded relations are reducible (in a sense to be specified) and therefore in my view not universals (cf. Armstrong 1997, 2004). But if they were not so reducible, they would, I believe, be universals.
} 
modus of 'truthmaking', for the simple reason that grounded relations are, as their name obviously shows, conceptualized in the former.) A further condition is needed, viz. that $5 \mathrm{ft} 11$ ins is taller than (or more than) $5 \mathrm{ft}$ 9ins. This condition is of course an internal relation holding between the two heights. Similarly in other cases: in addition to the two facts that are instantiations of the two relevant contingent properties, these properties need to stand in a characteristic relation. ${ }^{7}$ In many, perhaps most, cases, the properties will be quantities related by an internal relation, such as being taller than (or more than) holding between $5 \mathrm{ft} 11$ ins and $5 \mathrm{ft} 9$ ins.

Now it is easy to see what the relationship is between a grounded relation $\mathrm{R}_{\mathrm{G}}$ and an internal relation $R_{I}$ with the same name: the grounded relation holds if and only if the internal relation is the very internal relation that is involved in its grounding. For example, the grounded relation of being darker than holds between Sam's shirt and Kim's blouse if and only if the internal relation of being darker than holds between the colour of Sam's shirt and the colour of Kim's blouse.

Someone who accepts a traditional dichotomy of relations (internal vs. external) might object to our trichotomy as follows. Firsly, appealing to the broad, traditional sense of external relation we encountered above ('a relation is external if it need not relate the entities it relates'), she could say that the relation of being darker than between Sam's shirt and Kim's blouse is external (it need not hold between them, since Sam's shirt and Kim's blouse could have been the same shirt and the same blouse, but have been dyed differently). Secondly, she could maintain that the 'grounding' of this relation in the

\footnotetext{
${ }^{7}$ In my view, instantiations of properties (and relations) are facts or states of affairs (cf. Meinertsen 2008). However, nothing in this paper presupposes this ontology. For our present purposes, the notion of facts and its associated locutions can be taken as heuristic.
} 
actual colours of the shirt and the blouse is due not to a third kind or category of relation, but simply to the fact that the colour of the shirt is darker than the colour of the blouse (such that the internal relation of being darker than holds between these actual colours). She might add that this not only coheres with, but also explains my point about the equivocity of 'being darker than' ${ }^{8}$

If one takes this line, with only one kind of non-internal relation, which as it were is on a par with the internal one, it seems reasonable to require that one explain why the initial relation of being darker than between the items of clothing is external (in the traditional sense) in the first place.

The proponent of the objection construes this explanandum as equivalent to the question of where the contingency of the relation comes from. She maintains that it comes from the contingency of the fact that Sam's shirt has the colour it actually has and the contingency of the fact that Kim's blouse has the colour it actually has. ${ }^{9}$

It is correct that the facts that 'ground' the obtaining of the internal relation are contingent in this way in the example at issue, as well as in all other cases of grounded relations (in my sense). And although it is by no means obvious that 'externality' and contingency are equivalent in the required way, I shall assume for the sake of argument that they are. Given this, one might indeed say that precisely because the grounding facts are contingent, the contingency or 'externality' of the initial relation of being darker than

\footnotetext{
${ }^{8}$ I am grateful to an anonymous referee for Grazer Philosophische Studien for what in essence is this objection to my position, and I shall consider it in the remainder of this section.

${ }^{9}$ In addition, she construes the colours of the particulars as tropes. However, it seems to me that the objection does require that one accepts tropes.
} 
between the items of clothing is explained. Yet no third category or kind of relation has been invoked.

However, this explanation replies on an unfounded assumption, namely, the view that the contingency of the grounding facts explains why the intial relation is 'external' - by bestowing their modality on this relation, as it were. Or, to put it in a more ontological way, the claim is that the intial relation is 'external' in virtue of the grounding facts being contingent. But there is no reason why the necessity of the relevant internal relation should not just as well mean that the intial relation be internal, rather than 'external', which obviously it is not. This explanation therefore fails.

I am not aware of any alternative explanans. Fortunately, given our trichotomy, we need not account for the modality of grounded relations by contingent facts about their relata, or by any other facts for that matter. Since they are a third sui generis kind of relation (although ultimately reducible, in a sense to be specified below) their modality does not call for an explanation.

\section{Relations and ontological fundamentality}

Our definitions of internal, external and grounded relations neatly enable us to argue that only the second kind of entity is ontologically fundamental. What do I mean by 'ontologically fundamental'? For our purposes, for an entity to be ontologically fundamental is for it to exist at the level of truthmakers (cf. Armstrong 1997, 2004). For an entity to exist at the level of truthmakers is, roughly, for it to be a (proper or improper) part of the truthmaker of a statement. I shall say that an entity that (conversely) does not exist at this level is truthmaker-reducible (TM-reducible). For instance, on ('extreme') 
nominalism, if ' $a$ has relation $\mathrm{R}$ to $b$ ' is true, then $\mathrm{R}$ is TM-reducible: it is neither a proper nor improper part of the truthmaker of this (or any other) statement. On realism, by contrast, $\mathrm{R}$ is not TM-reducible, since it is a part of the truthmaker of this statement (in my view, the state of affairs of $a$ 's having $\mathrm{R}$ to $b$ ). ${ }^{10}$ Similarly for the monadic case on either nominalism or realism. This truthmaker-based view of ontological fundamentality is broadly Armstrongian (cf. ibid.). It is beyond the scope of this paper to explain it any further. Fortunately, however, if we can define the three kinds of relation satisfactorily, the present sketch suffices for the additional objective of separating external relations from internal and grounded relations in the required sense of ontological fundamentality. All we need is the view that the truthmaker of a true statement $s$ that states or expresses an internal or grounded relation, $\mathrm{E}^{*}$, does not include $\mathrm{E}^{*}$; but if $s$ states or expresses an external relation, it does.

Consider first internal relations. It is logically impossible for any of these pairs of relata to coexist without the relation holding between them. Hence, these pairs make true the statements that state or express the internal relations, such as 'triangularity is contrary to squareness', i.e. the internal relations are not included in the truthmakers of these statements. Thus, they are TM-reducible. Although they are 'basic', in the sense of being theoretically important in metaphysics, they are not ontologically fundamental. This is of course an economically welcome result.

By contrast, it obviously follows from (ER) that external relations are TMirreducible, or equivalently, instantiations of them are needed as truthmakers of

\footnotetext{
10 Provided of course that, as Armstrong has emphasized, $\mathrm{R}$ is part of the 'scientific', as opposed to the 'manifest', image of the world - a fact which we determine a posteriori.
} 
statements that an external relation is holding. ${ }^{11}$ They are, therefore, ontologically fundamental.

What about grounded relations? Does the grounded relation stated or expressed by a true statement exist at the level of truthmakers? No. The grounding or truthmaking of a grounded relation $\mathrm{R}_{\mathrm{G}}$ holding between $a$ and $b$ involves merely the instantiation of the relevant contingent properties by $a$ and $b$, in conjunction with the specific internal relation $R_{I}$ holding between these properties. To put it more formally, if the fact of $R_{I}(F$, $\mathrm{G}) \&(\mathrm{~F} a \& \mathrm{G} b)$ exists, then the statement ' $a$ stands in $\mathrm{R}_{\mathrm{G}}$ to $b$ ' is true - i.e. the former is the truthmaker of the latter. In our example, if the fact of $5 \mathrm{ft} 11$ ins being more than $5 \mathrm{ft} 9$ ins \& (Kim's being $5 \mathrm{ft} 11$ ins \& Sam's being $5 \mathrm{ft} 9$ ins) exists, then it makes true 'Kim is taller than Sam'. There is no grounded relation at the truthmaker level. Thus, grounded relations are not ontologically fundamental. ${ }^{12}$

\section{Conclusion}

If what I have argued in this paper is correct, there are not two basic kinds of relation, but three: internal, external, and grounded relations. The Standard View is thus crude in its failing to distinguish the last kind from internal relations on the one hand, and from external relations on the other. However, I argued that grounded relations do not exist at

\footnotetext{
11 Again, provided that the relations in case are part of the 'scientific' image of the world (cf. footnote 7).

12 Note that my analysis of grounded relations shows us that my view of internal and grounded relations as reducible (in the sense of TM-reducible), should not be confused with the view that they (and external relations) are 'reducible to (non-relational) properties of their relata' in the sense of 'foundationism' (the properties in case being 'foundations' for the relation). I believe this view is untenable, cf. Russell (1903). Contrast this with the contemporary defence of foundationism of Keith Campbell ('The Place of Relations in a Trope Philosophy', MS).
} 
the level of truthmakers, and that, ironically, this view is nonetheless thus correct that only external relations are ontologically fundamental.*

\section{References}

Armstrong, David. M. 1978: Universals and Scientific Realism. Cambridge: Cambridge University Press.

--- $\quad$ 1997: A World of States of Affairs. Cambridge: Cambridge University Press.

--- 2004: Truths and Truthmakers. Cambridge: Cambridge University Press.

Bennett, Jonathan 1988: Events and Their Names. Oxford: Clarendon Press.

Campbell, Keith 1990: Abstract Particulars. Oxford: Blackwell.

--- "The Place of Relations in Trope Theory". Unpublished MS.

Johansson, Ingvar 1990: Ontological Investigations. London: Routledge.

Lewis, David 1983: "Events". In his: Philosophical Papers, II.., Oxford: Oxford University Press, 241-269.

Lombard, Lawrence B. 1986: Events: A Metaphysical Study. London: Routledge and Kegan Paul.

Meinertsen, Bo 2008: "A Relation as the Unifier of States of Affairs". dialectica 62, 1-19.

Mulligan, Kevin 1995: "Internal Relations". In Jaegwon Kim \& Ernest Sosa (eds.), A Companion to Metaphysics. Oxford: Blackwell, 245-246.

--- 1998: "Relations - through Thick and Thin". Erkenntnis 48, 325-353.

Russell, Bertrand 1903: The Principles of Mathematics. Cambridge: Cambridge University Press.

--- $\quad$ 1910: "Some Explanations in Reply to Mr. Bradley". Mind 19, 373-378.

Vallicella, William F. 2002: "Relations, Monism, and the Vindication of Bradley's Regress". dialectica $56,3-35$.

\footnotetext{
* I would like to thank George Darby, Hugh Mellor, Scott Shalkowski, Peter Simons and an anonymous referee for extensive comments on earlier drafts of this paper or discussions about the metaphysics and ontology of relations.
} 